ARTICLE

\title{
In-situ anodic precipitation process for highly efficient separation of aluminum alloys
}

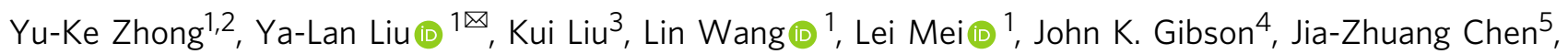
Shi-Lin Jiang ${ }^{1,2}$, Yi-Chuan Liu', Li-Yong Yuan', Zhi-Fang Chai ${ }^{5} \&$ Wei-Qun Shi ${ }^{1}{ }^{1}$

Electrorefining process has been widely used to separate and purify metals, but it is limited by deposition potential of the metal itself. Here we report in-situ anodic precipitation (IAP), a modified electrorefining process, to purify aluminium from contaminants that are more reactive. During IAP, the target metals that are more cathodic than aluminium are oxidized at the anode and forced to precipitate out in a low oxidation state. This strategy is fundamentally based on different solubilities of target metal chlorides in the $\mathrm{NaAlCl}_{4}$ molten salt rather than deposition potential of metals. The results suggest that IAP is able to efficiently and simply separate components of aluminum alloys with fast kinetics and high recovery yields, and it is also a valuable synthetic approach for metal chlorides in low oxidation states.

\footnotetext{
${ }^{1}$ Laboratory of Nuclear Energy Chemistry, Institute of High Energy Physics, Chinese Academy of Sciences, 100049 Beijing, China. ${ }^{2}$ University of Chinese Academy of Sciences, 100049 Beijing, China. ${ }^{3}$ Sino-French Institute of Nuclear Engineering and Technology, Sun Yat-sen University, 519000 Zhuhai, China. ${ }^{4}$ Chemical Sciences Division, Lawrence Berkeley National Laboratory (LBNL), Berkeley, CA 94720, USA. ${ }^{5}$ Engineering Laboratory of Advanced Energy Materials, Ningbo Institute of Industrial Technology, Chinese Academy of Sciences, 315201 Ningbo, China. email: liuyalan@ihep.ac.cn; shiwq@ihep.ac.cn
} 
ttributes of aluminum and its alloys include light weight, high strength and excellent corrosion resistance, which have led to widespread applications ${ }^{1}$. In the nuclear field, aluminum is a component of fuel $\left(\mathrm{UO}_{2} / \mathrm{Al}, \mathrm{U}-\mathrm{Si} / \mathrm{Al}, \mathrm{U}-\mathrm{Mo} / \mathrm{Al}\right.$, and $\mathrm{U}-\mathrm{Al} / \mathrm{Al}$ ) and fuel cladding ${ }^{2}$, and is also among the most promising metallic solvents and electrode materials for actinidelanthanide pyroprocessing separations ${ }^{3}$. However, handling the resulting radioactive aluminum alloys by aqueous reprocessing can be challenging as its use of strong acids for dissolution may be complex and will generate abundant radioactive liquid waste ${ }^{3}$, while by chlorination route use of reactive gases like $\mathrm{Cl}_{2}$ or $\mathrm{HCl}$ for high-temperature chlorination will corrode equipment and present additional hazards ${ }^{4}$.

Electrochemical technologies are widely used in synthesis ${ }^{5-7}$, metal extraction ${ }^{8,9}$, energy conversion ${ }^{10-13}$, and separations ${ }^{14,15}$. Due to unique features enabled by physical separation of the cathode and anode, an electrochemical technique can be tailored for specific components, often with high efficiency and product purity, and at low $\operatorname{cost}^{16}$. In a typical electrochemical separation the cathode potential is controlled to selectively deposit the desired product, while other components remain dissolved in the electrolyte, with the separation efficiency dependent on the difference in reduction potentials of the desired product and the other components ${ }^{17}$. However, the traditional electrochemical separation approaches are often challenging or impractical for $\mathrm{Al}$ alloys, especially those containing active metals that are electrochemically oxidized at more negative potentials than oxidation potential of $\mathrm{Al}^{0} / \mathrm{Al}^{3+18,19}$. Usually, these active metals will preferentially dissolve at the anode to form metal ions, and co-reduce with $\mathrm{Al}^{3+}$ at the cathode to form $\mathrm{Al}$ alloys again due to the small difference deposition potential of these active metals, making them difficult to be separated.

Here, we report a different anodic process, in-situ anodic precipitation (IAP), to separate target metals from aluminum alloy components. In IAP, the target metals can be precipitated at the anode immediately after oxidation, by combining with chloride in the $\mathrm{NaAlCl}_{4}$ molten salt electrolyte, in contrast to typical electrochemical approaches in which soluble ions or gases like $\mathrm{O}_{2}, \mathrm{Cl}_{2}$, or $\mathrm{CO}_{2}$ are generated at the anode. The key to IAP for the separation is thus a difference in metal ion solubilities, rather than a difference in reduction potentials of metals. To evaluate the IAP method, results are reported for separation of aluminum from typical alloy constituents $\mathrm{U}, \mathrm{Ti}$, and representative lanthanides. In addition to demonstrating IAP as effective for separation of $\mathrm{Al}$ alloys, the results reveal it as a different approach to prepare metal chlorides in low oxidation states.

\section{Results}

Overview of the IAP process. Fig. 1a is a schematic diagram of the IAP process for separating $\mathrm{Al}$ from a metal $\mathrm{M}$ in binary alloy $\mathrm{Al}-\mathrm{M}$, and Fig. $1 \mathrm{~b}$ presents the images obtained by electrolysis with different anodes. The anode is the alloy and the cathode is a conductive metal such as pure $\mathrm{Al}$. In operation, alloy constituents $\mathrm{M}$ and $\mathrm{Al}$ are oxidized to $\mathrm{M}^{\mathrm{n}+}$ and $\mathrm{Al}^{3+}$. While $\mathrm{Al}^{3+}$ is soluble in the electrolyte ${ }^{20}$, as $\mathrm{AlCl}_{4}{ }^{-}$or $\mathrm{Al}_{2} \mathrm{Cl}_{7}{ }^{2-}$, insoluble $\mathrm{M}^{\mathrm{n}+}$ formed at the anode rapidly combines with chloride anions to form an insitu precipitate of solid $\mathrm{MCl}_{\mathrm{x}}$ very close to the anode surface. Cogeneration of soluble $\mathrm{Al}$ species at the anode induces continuous flaking and removal of the precipitate from the anode surface, which maintains an electrochemically active interface. At the cathode, dissolved $\mathrm{Al}^{3+}$ is reduced to aluminum metal and codeposited with $\mathrm{NaCl}$. Advantages of $\mathrm{NaAlCl}_{4}$ molten salt as the electrolyte include good ionic conductivity, a low melting point of $426 \mathrm{~K}$ with resultant low operating temperature, and low density and viscosity 20,21 . The IAP separation approach is enabled by low solubility of actinide, lanthanide, and transition metal chlorides in the electrolyte at the operating temperature, for neutral or alkaline conditions with $\mathrm{AlCl}_{3}$ content of $50 \mathrm{~mol} \%$ or less ${ }^{22,23}$. The low viscosity and density of the melt facilitates detachment of the precipitate from the anode, with product accumulation beneath the anode at the bottom of the electrochemical cell enabling separation by simply decanting the electrolyte.

Separation of $\mathbf{U}$ and Al. Pure $\mathrm{U}$ metal and Al-U alloy anodes were both employed to demonstrate general performance of IAP. These anodes before and after electrolysis are shown in Fig. 2a, b, where it is apparent that both surfaces were highly corroded by electrolysis, with the pure $U$ anode particularly damaged and coarse. Fig. $2 \mathrm{c}$, d show the current versus time curves for $U$ and Al- $U$ anodes at three potentials. No significant current for the $U$ anode is observed for an applied potential of $1 \mathrm{~V}$ vs. Al, presumably because adhesion of initial oxidation products prevents further reaction. As the $\mathrm{U}$ anode potential is increased to $2 \mathrm{~V}$ and then $3 \mathrm{~V}$ vs. Al, the current density increases, which suggests that anode passivation is overcome, with a result that kinetics are highly dependent on anode polarization. Passivation of the anode is evidently rate-determining, and a high electrode potential greatly accelerates the IAP process. The inset of Fig. $2 \mathrm{~d}$ shows marked current oscillations with electrolysis time, possibly with some periodicity. The IAP oscillations presumably reflect precipitation and elimination of $\mathrm{UCl}_{3}$ from the anode (Supplementary Fig. 1). X-ray diffraction (XRD) analysis such as in Fig. $2 \mathrm{f}$

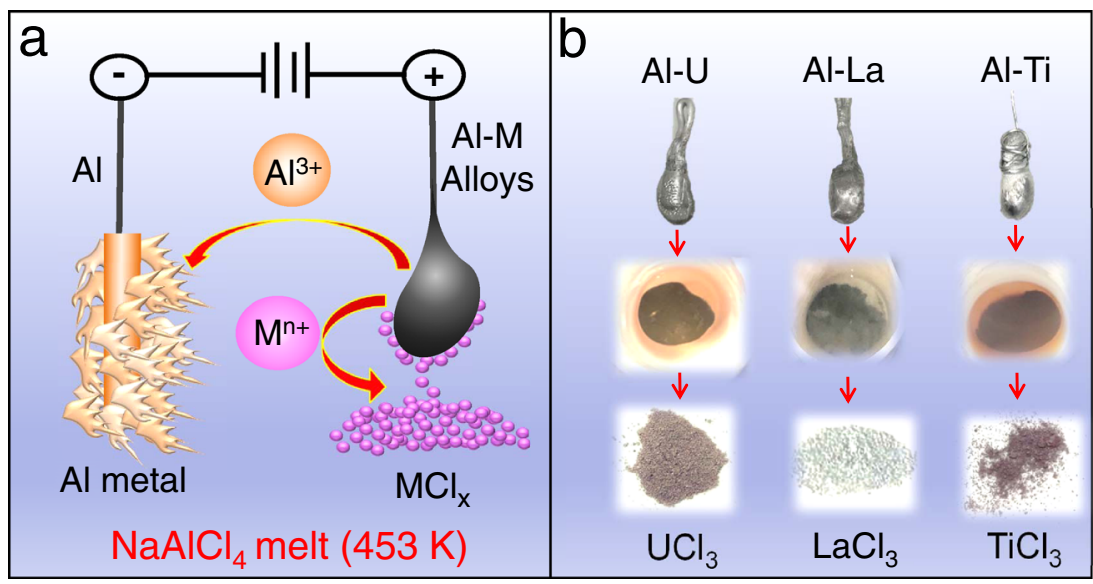

Fig. 1 Schematic of the IAP process. a Schematic illustration of the IAP process in $\mathrm{NaAICl}_{4}$ molten salt electrolyte. b $\mathrm{Various}$ alloys and corresponding metal chlorides precipitated in the bottom of crucible by electrolysis with different anodes and final metal chloride products obtained. 

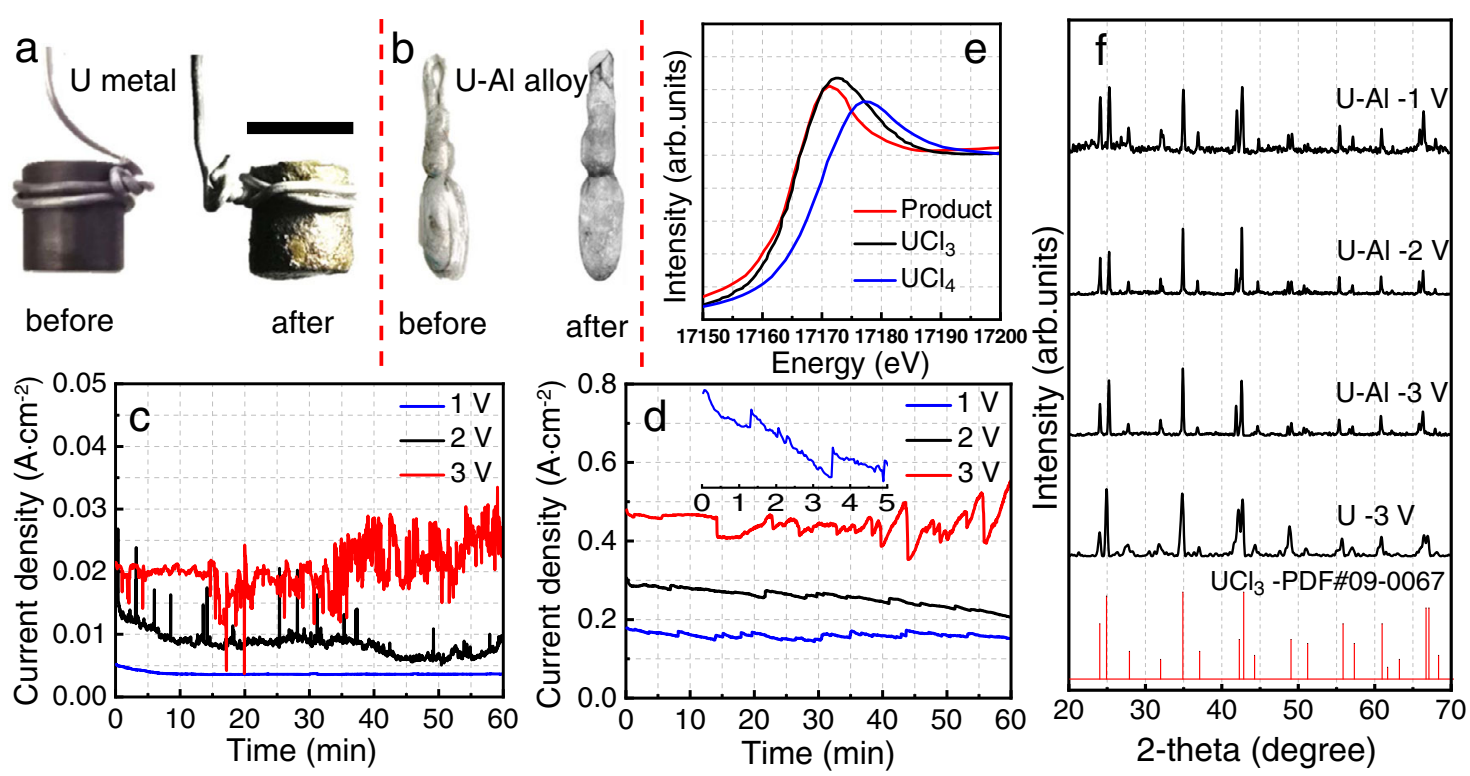

Fig. 2 Anodic processes of $\mathbf{U}$ and $\mathbf{A l}-\mathbf{U}$ alloy. Images of $\mathbf{a} U$ metal anode and $\mathbf{b} \mathrm{Al}-\mathrm{U}$ alloy anode before and after electrolysis. Scale bar $=1 \mathrm{~cm}$. Current versus time plots for three electrode potential using $\mathbf{c} U$ anode and $\mathbf{d ~ A l - U}$ alloy anode in $\mathrm{NaAICl}_{4}$ melt at $453 \mathrm{~K}$. e U $\mathrm{L}_{3}$-edge XANES spectra of standards $\mathrm{UCl}_{4}$ and $\mathrm{UCl}_{3}$, and the $\mathrm{U}$ anode product of electrolysis at $3 \mathrm{~V}$ vs. Al (quenched suddenly to the solid state at room temperature without any other treatment). $\mathbf{f} X R D$ patterns of anode products after electrolysis of pure $\mathrm{U}$ at $3 \mathrm{~V}$ and the $\mathrm{Al}-\mathrm{U}$ alloy at $1 \mathrm{~V}, 2 \mathrm{~V}$ and $3 \mathrm{~V}$ vs. $\mathrm{Al}$; and standard pattern for $\mathrm{UCl}$.
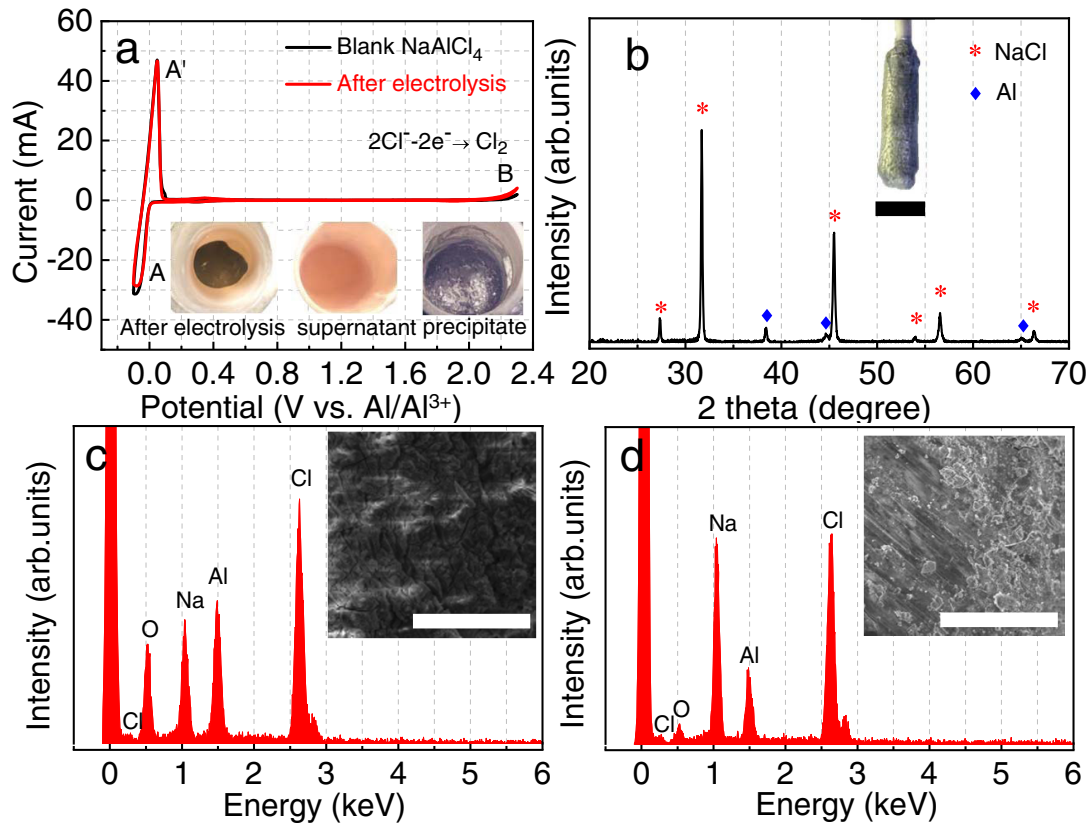

Fig. 3 Analyses of electrolyte and cathode after IAP. a CV curves of $\mathrm{NaAlCl}_{4}$ melt before (black line) and after electrolysis (red line); insets are photos looking down into the anode crucible after electrolysis, and of the separated supernatant and precipitate. $\mathbf{b}$ XRD pattern of the cathode product after electrolysis, with a photo of the cathode. Typical EDS analyses of $\mathbf{c}$ electrolyte and $\mathbf{d}$ cathode product after electrolysis; insets are the corresponding SEM images. The scale of $\mathbf{b}$ is $1 \mathrm{~cm}$ and $\mathbf{c}, \mathbf{d}$ is $100 \mu \mathrm{m}$.

reveals crystalline product $\mathrm{UCl}_{3}$, with no apparent side reactions even for an anodic oxidation potential above that for evolution of $\mathrm{Cl}_{2}(2.30 \mathrm{~V}$ vs. $\mathrm{Al}$ shown in Fig. 3a). Extended X-ray absorption fine structure (EXAFS) characterization (Fig. 2e and Supplementary Fig. 2, Supplementary Table 1) of the IAP anodic precipitate after electrolysis at $3 \mathrm{~V}$ provided the $\mathrm{U}$ oxidation state and local coordination environment ${ }^{24,25}$ in good agreement with XRD (Fig. 2f). Given that $\mathrm{U}^{3+}$ is typically oxidized to $\mathrm{U}^{4+}$ at such a high potential, this result suggests $\mathrm{U}^{3+}$ is trapped in the precipitate, preventing its further oxidation.
Current vs. time curves for the Al-U alloy anode exhibit the same general behavior as for the $\mathrm{U}$ anode, but with greater current density of up to $0.5 \mathrm{~A} / \mathrm{cm}^{2}$ at $3 \mathrm{~V}$ vs. $\mathrm{Al}$ (Fig. 2d). The higher current for Al-U suggests that formation of soluble ions like $\mathrm{AlCl}_{4}{ }^{-}$promotes detachment of precipitates which maintains an active electrode surface. For the $\mathrm{U}$ and Al-U electrodes at $3 \mathrm{~V}$ vs. Al, the current density generally increases with the time of the electrolysis (Fig. 2c, d), possibly due to an effect of active electrode surface increase. As $U$ is oxidized, the anode surface gets more "structured", uneven, and rough (Supplementary Fig. 1b), which 
leads to an increase of anodic active surface. On the other hand, smilar senario on the cathode occurs as dendritic aluminum deposited at the same time, which increases the cathodic active surface, then the current will increase correspondingly. XRD analysis of the $\mathrm{UCl}_{3}$ precipitate from the $\mathrm{Al}-\mathrm{U}$ anode indicates highly crystalline material. Cyclic voltammograms $(\mathrm{CV})$ of the $\mathrm{Al}-\mathrm{U}$ anode product in $\mathrm{LiCl}-\mathrm{KCl}$ reveals no features due to metals other than U (Supplementary Fig. 3), indicating a purity suitable for use in nuclear fuel cycle 26,27 . The recovery yield of $U$ is $94.6 \%$ (Supplementary Eq. 2) as determined from the electrode mass before and after electrolysis. It is worthnoting that the results reported above were achieved by using $\mathrm{U}-\mathrm{Al}$ alloy anode prepared by melting. On the other hand, we studied the IAP process using an alternative Al-U alloy anode prepared by electrolysis, in which the alloy cann't be compeletely separated possibly due to its poor mechanical properties (Supplementary Fig. 4), demonstrating the advantages of utilization of alloys prepared by the high temperature processing.

The inset in Fig. 3a shows the electrolyte and precipitate after electrolysis. The clear supernatant electrolyte and dark anode precipitate at the bottom of the crucible are clearly distinct from one another, and are easily separated by simply decanting the electrolyte. The separated electrolyte was analyzed by $\mathrm{CV}$, Scanning electron microscopy-energy-dispersive X-ray spectroscopy (SEM-EDS), and ICP-MS. CV curves of $\mathrm{NaAlCl}_{4}$ before and after electrolysis are essentially coincident, as in Fig. 3a. The absence of uranium electrochemical response after IAP in the CV potential window between aluminum electrodeposition at $0 \mathrm{~V}$ (peak A) and chlorine evolution $\sim 2.3 \mathrm{~V}$ (peak B) indicates low solubility of $\mathrm{UCl}_{3}$ in $\mathrm{NaAlCl}_{4}$ at $453 \mathrm{~K}$. Consistent with the $\mathrm{CV}$ results, $\mathrm{U}$ was not detected in the melt by SEM-EDS analysis (Fig. 3c). Furthermore, solubility product constant (Ksp) of $\mathrm{UCl}_{3}$ was determined to be $1.20 \times 10^{-16}$ by ICP-MS, as shown in the Table 1, which once again indicates the concentration of $U$ in the melt is very low. Therefore, the reaction of uranium at the anode can be expressed as Eqs. 1 and 3.

Generally, electrodeposition of $\mathrm{Al}$ (Eq. 2) was claimed to be a typically cathodic reaction in $\mathrm{AlCl}_{3}$-based melt ${ }^{20}$. However, the XRD pattern (Fig. $3 \mathrm{~b}$ ) of the cathode here indicates it is a mixture of $\mathrm{NaCl}$ and $\mathrm{Al}$, in good agreement with SEM-EDS result as shown in Fig. 3d, which is due to the low solubility of $\mathrm{NaCl}$ in the melt and its slow dissolution kinetics, making it precipitated insitu at the cathode, as described in Eq. 4. As a result, the growth of cathode dendrite is much inhibited. Related evidence is clearly shown from the rod-shaped cathode after electrolysis (inset of Fig. 3b), which becomes flake-shaped after further washing (inset of Supplementary Fig. 5b). Therefore, the total process of IAP based on the reactions between anode and electrolyte to produce anode precipitates and cathode products can be depicted in Eqs. 1-5 as follows:

$$
\begin{gathered}
(+) \mathrm{U}_{\text {(anode) }} \rightarrow \mathrm{U}^{3+}+3 \mathrm{e}^{-} \\
(-) \mathrm{NaAlCl}_{4}+3 \mathrm{e}^{-} \rightarrow \mathrm{Al}_{(\text {cathode })}+4 \mathrm{Cl}^{-}+\mathrm{Na}^{+}
\end{gathered}
$$

\begin{tabular}{|c|c|c|c|}
\hline Anode & Product & Ksp & Yield (\%) \\
\hline $\bar{U} / \mathrm{U}-\mathrm{Al}$ & $\mathrm{UCl}_{3}$ & $1.20 \times 10^{-16}$ & 94.6 \\
\hline $\mathrm{La} / \mathrm{La}-\mathrm{Al}$ & $\mathrm{LaCl}_{3}$ & $1.15 \times 10^{-16}$ & 97.0 \\
\hline $\mathrm{Sm}$ & $\mathrm{SmCl}_{2}$ & $3.76 \times 10^{-9}$ & 88.7 \\
\hline $\mathrm{Eu}$ & $\mathrm{EuCl}_{2}$ & $2.47 \times 10^{-9}$ & 90.4 \\
\hline $\mathrm{Yb}$ & $\mathrm{YbCl}_{2}$ & $1.83 \times 10^{-9}$ & 94.1 \\
\hline Ti/Ti-Al & $\mathrm{TiCl}_{3}$ & $5.22 \times 10^{-14}$ & 80.5 \\
\hline
\end{tabular}

$$
\begin{gathered}
\mathrm{U}^{3+}+3 \mathrm{Cl}^{-} \rightarrow \mathrm{UCl}_{3(\text { ppte })} \\
\mathrm{Na}^{+}+\mathrm{Cl}^{-} \rightarrow \mathrm{NaCl}_{(\text {ppte })} \\
\mathrm{U}_{\text {(anode) }}+\mathrm{NaAlCl}_{4} \rightarrow \mathrm{UCl}_{3 \text { (ppte) }}+\mathrm{Al}_{\text {(cathode) }}+\mathrm{NaCl}_{\text {(ppte) }}
\end{gathered}
$$

The recovery yield of aluminum is up to $99.4 \%$. In addition, XRD and SEM-EDS analyses of the cathode product after washing (Supplementary Fig. 5) confirm its aluminum metal nature, which once again proves that uranium will not be deposited on the cathode. Chlorine and oxygen impurities may respectively result from electrolyte adhesion to the surface and reaction with air. Further, uranium is not detected from the cathode product by ICP-MS. The absence of uranium in both the electrolyte and cathode after IAP demonstrates effective separation of $\mathrm{U}$ from the Al-U alloy. However, $\mathrm{U}$ is not completely recovered at the anode $(94.6 \%$, see Table 1$)$, most likely due to the adhesion of its precipitates on the cathode rather than chemical deposition. This phenomenon is also observed in the IAP of divalent rare earth (Supplementary Fig. 8).

Separation of lanthanides and titanium from Al. To assess its wider applicability, the IAP approach is extended to Allanthanide and Al-titanium alloys. Results for La, a representative lanthanide, are in Supplementary Fig. 6, where it is apparent that surface material is removed from both the La and Al-La alloy anodes during electrolysis. Figure $4 \mathrm{a}, \mathrm{b}$ show current versus time curves for these anodes at three potentials; addition of $\mathrm{Al}$ to $\mathrm{La}$ greatly enhances the dissolution rate, as seen above when comparing $\mathrm{U}$ and $\mathrm{Al}-\mathrm{U}$. The grayish anode product shown in the inset of Fig. $4 \mathrm{c}$ is identified by XRD as crystalline $\mathrm{LaCl}_{3}$. Also studied as IAP anodes were pure $\mathrm{Sm}, \mathrm{Eu}$, and $\mathrm{Yb}$, and both pure $\mathrm{Ti}$ and an Al-Ti alloy (Supplementary Figs. 7-9). All four of these metals are precipitated in low oxidation states in the anode products, specifically $\mathrm{SmCl}_{2}, \mathrm{EuCl}_{2}, \mathrm{YbCl}_{2}$, and $\mathrm{TiCl}_{3}$ as shown in Fig. $4 \mathrm{~d}$ and Supplementary Fig. 9d. These oxidation states are obtained at an anodic oxidation potential of $3.0 \mathrm{~V}$ vs. Al, which is above the limit for chlorine evolution. Retention of low oxidation states is further demonstration that the composition of the anode product is largely independent of the applied potential, which contrasts with usual electrochemical behavior. The much slower oxidation kinetics for anodes of $\mathrm{Ti}$ and $\mathrm{Al}-\mathrm{Ti}$ alloy (Supplementary Fig. 9a, b), vs. La and Al-La, presumably reflects some sort of passivation of Ti. Formation of trivalent $\mathrm{Ti}$ as $\mathrm{TiCl}_{3}$ as the anode precipitate product is particularly remarkable. In addition, high-temperature vaporization to separate $\mathrm{TiCl}_{3}$ from $\mathrm{NaAlCl}_{4}$ transforms trivalent $\mathrm{Ti}$ to other oxidation states ${ }^{28,29}$, which is not obeserved in the divalent lanthanide chlorides. A separate later effort will further assess IAP for synthesis of compounds containing Ti (III) and other low oxidation state metals (Supplementary Fig. 10).

The Ksp and recovery yields of several different anodes for IAP are listed in Table 1 . The recovery yields of trivalent chlorides are significantly higher than that of divalent ones, suggesting very low solubility of trivalent chlorides in this electrolyte, which is well in agreement with the evolution trend of Ksp. For the divalent chlorides, the recovery yield of $\mathrm{YbCl}_{2}$ is higher than that of $\mathrm{SmCl}_{2}$ and $\mathrm{EuCl}_{2}$, which is correlated with the lower solubility of divalent $\mathrm{Yb}$ in the electrolyte and is also consistent with Ksp and EDS results (Supplementary Fig. 8). In addition, $\mathrm{YbCl}_{2}$ often falls off from the anode in big flakes, making it even easier to be completely separated and recovered from the electrolyte. 

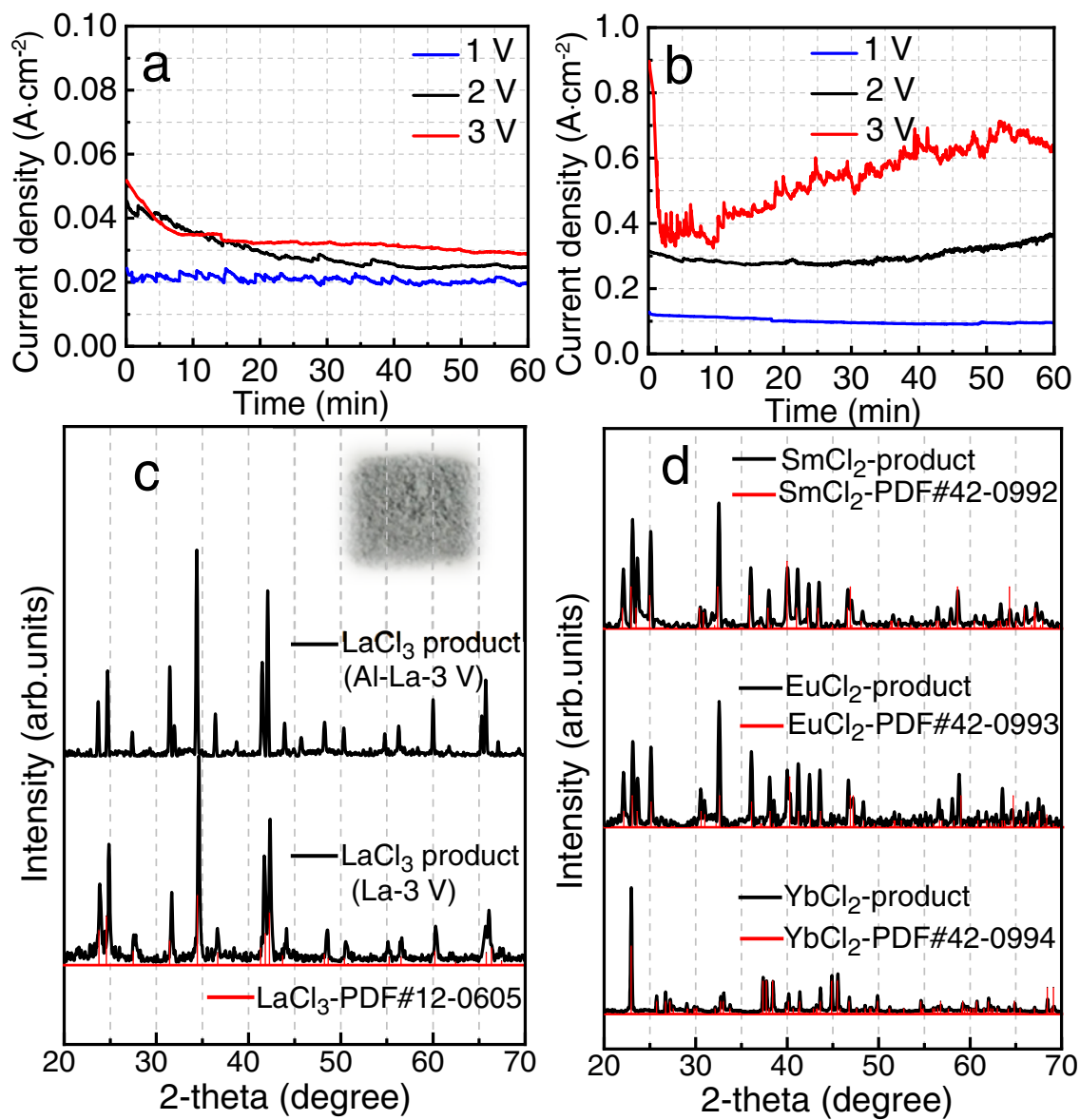

Fig. 4 Anodic processes of lanthanides. Current vs. time plots at three electrode potentials in $\mathrm{NaAlCl}_{4}$ melt at $453 \mathrm{~K}$ using as the anode $\mathbf{a} \mathrm{La}$ and $\mathbf{b} \mathrm{Al}-\mathrm{La}$ alloy. c XRD patterns of IAP anode precipitates for La and Al-La anodes; the inset is a photo of the $\mathrm{LaCl}_{3}$ product. $\mathbf{d}$ XRD patterns of precipitates from Sm, $\mathrm{Eu}$, and $\mathrm{Yb}$ anodes.

\section{Discussion}

Herein, the IAP process has been demonstrated in $\mathrm{NaAlCl}_{4}$ molten salt electrolyte, using several metals and their alloys with Al. Especially, efficiently direct separation of $\mathrm{U}-\mathrm{Al}$ alloys has been achieved in a one-step manner with high-purity $\mathrm{UCl}_{3}$ precipitate at the anode and pure $\mathrm{Al}$ deposited at the cathode under mild conditions with high recovery yield. As the IAP method employs different solubilities of anode products, rather than different reduction potentials for deposition, it is not limited by an electrochemical window or cathode potential. In addition, increasing the anodic potential and/or the aluminum content in the alloy provides rapid oxidation/precipitation kinetics. Furthermore, the simplicity of IAP indicates it as a practical approach for the separation of active metals in aluminum alloys and, in light of the results presented in this study, shows promise for extension to the production of high-purity and low oxidation state compounds at low temperatures. It is inspiring that the so-called IAP approach we propose could be possibly extended to other electrolytes, not only based on $\mathrm{AlCl}_{3}$, but also other Lewis acid electrolyte and room temperature electrolytes ${ }^{21,30-32}$. More in-depth studies are needed to optimize the method; the initial results reported here suggest broad applicability for separations and material preparation.

\footnotetext{
Methods

Electrolytic apparatus and procedures. The photograph of experimental setup are shown in Supplementary Fig. 11. An alumina crucible (inner diameter: $52 \mathrm{~mm}$ ) containing $\sim 150 \mathrm{~g} \mathrm{NaAlCl}_{4}$ electrolyte was fixed in a specified programmable electric furnace. Metals or aluminum alloys were used as the working electrode (WE). An aluminum $\operatorname{rod}(\Phi=3 \mathrm{~mm}, 99.999 \%)$ was the counter electrode (CE), and the reference electrode $(\mathrm{RE})$ was an aluminum wire $(\Phi=1 \mathrm{~mm}, 99.999 \%)$ inserted in a pyrex glass tube $(\Phi=6 \mathrm{~mm})$ filled with $\mathrm{NaAlCl}_{4}$ melt (Supplementary
}

Fig. 11c $)^{33}$. Electrolysis experiments were carried out using an Autolab PGSTAT $302 \mathrm{~N}$ in a potentiostatic mode, keeping a potential of $1 \mathrm{~V}, 2 \mathrm{~V}$ or $3 \mathrm{~V}$ vs. $\mathrm{Al}$, respectively. All operations were performed in a glove box with moisture and oxygen maintained below $3.0 \mathrm{ppm}$. The temperature of the melt was measured with a K-type thermocouple $( \pm 2 \mathrm{~K})$, with the electrolysis temperature maintained at $453 \pm 5 \mathrm{~K}$. The surface areas of the electrodes were calculated by measuring the depth of the wetting electrode immersed in $\mathrm{NaAlCl}_{4}$ melt after each experiment. At the end of the electrolysis experiment, the setup was left to set at $453 \mathrm{~K}$ for $8 \mathrm{~h}$ and the upper layer of electrolyte was separated by decanting to obtain the bottom precipitates. Some collected $U$ anode precipitates were quenched for EXAFS analysis. Then, they were distilled at $773 \mathrm{~K}$ for $8 \mathrm{~h}$ to remove the $\mathrm{NaAlCl}_{4}$ molten salt electrolyte adhering to its surface for XRD analyses. However, for the precipitates obtained from Al-Mo, Al-Ti anodes, they were vacuum distilled at $573 \mathrm{~K}$ for $1 \mathrm{~h}$ because of their poor stability at high temperature ${ }^{28}$.

Preparation of electrolyte and electrodes. $\mathrm{NaAlCl}_{4}$ molten salt electrolyte was prepared using anhydrous sodium chloride $(>99.9 \%)$ and aluminum chloride $(>99.5 \%)^{23}$. First, aluminum chloride and sodium chloride mixture $(1: 1)$ was put into an alumina crucible, heated to $473 \mathrm{~K}$ with a heating rate of $10 \mathrm{~K} / \mathrm{min}$ and kept at this temperature for $10 \mathrm{~h}$. Then, the melt was naturally cooled to $453 \mathrm{~K}$, and two aluminum rods $(\Phi=3 \mathrm{~mm}, 99.999 \%)$ were used as cathode and anode, respectively. Colorless and transparent electrolyte can be obtained after 3 days of electrolysis under the voltage of $1 \mathrm{~V}$ vs. Al. The uranium electrode was a cylindrical $\mathrm{U}$ metal ingot $(99.5 \%$, diameter $\Phi=1.0 \mathrm{~cm}$; length $=1.0 \mathrm{~cm})$ wrapped with aluminum wire. The other pure metal anodes ( $\mathrm{La}, \mathrm{Sm}, \mathrm{Eu}, \mathrm{Yb}$, and Ti with $99.5 \%$ purity) were prepared similarly. The Al-U alloys were $\sim 5 \mathrm{~mm}$ in diameter which were prepared by melting uranium (60 wt\%) and aluminum $(99.999 \%)$ in a vacuum furnace; the $\mathrm{Al}-\mathrm{La}, \mathrm{Al}-\mathrm{Mo}$, and $\mathrm{Al}-\mathrm{Ti}$ alloys were prepared similarly. Prior to the experiments, all anodes were polished with 1200 mesh silicon carbide sandpaper and cleaned with alcohol. The detailed conditions for CV testing are described in Supplementary methods.

Characterizations. X-ray absorption near edge structure and EXAFS spectra at the $\mathrm{U} \mathrm{L}_{3}$-edge were collected at beamline $1 \mathrm{~W} 1 \mathrm{~B}$ of the Beijing Synchrotron Radiation 
Facility using transmission mode ${ }^{34}$. XRD (Bruker, D8 Advance) was used for phase analysis. SEM (Hitachi S-4800)-EDS (GENESIS 2000) were used for surface morphology and composition analysis.

\section{Data availability}

The authors declare that all data supporting the findings of this study are either provided in the article and its Supplementary Information or available from the corresponding author upon request.

Received: 6 February 2021; Accepted: 10 September 2021; Published online: 01 October 2021

\section{References}

1. Lumley, R. Fundamentals of Aluminium Metallurgy: Production, Processing and Applications (Elsevier, 2010).

2. Nawaz, A., Mirza, S. M., Mirza, N. M. \& Sohail, M. Analysis of core life-time and neutronic parameters for HEU and potential LEU/MEU fuels in a typical MNSR. Ann. Nucl. Energy 47, 46-52 (2012).

3. Taylor, R. Reprocessing and Recycling of Spent Nuclear Fuel (Elsevier, 2015).

4. Meier, R. et al. Recovery of actinides from actinide-aluminium alloys by chlorination: part III-chlorination with $\mathrm{HCl}(\mathrm{g})$. J. Nucl. Mater. 498, 213-220 (2018).

5. Xiao, W., Zhou, J., Yu, L., Wang, D. \& Lou, X. W. Electrolytic formation of crystalline Silicon/Germanium alloy nanotubes and hollow particles with enhanced lithium-storage properties. Angew. Chem. Int. Ed. 55, 7427-7431 (2016).

6. Yuan, Y., Xiao, W., Wang, Z., Fray, D. J. \& Jin, X. Efficient nanostructuring of Silicon by electrochemical alloying/dealloying in molten salts for improved lithium storage. Angew. Chem. Int. Ed. 57, 15743-15748 (2018).

7. Zou, X. et al. Electrodeposition of crystalline silicon films from silicon dioxide for low-cost photovoltaic applications. Nat. Commun. 10, 5772 (2019).

8. Yin, H., Chung, B. \& Sadoway, D. R. Electrolysis of a molten semiconductor. Nat. Commun. 7, 12584 (2016)

9. Wang, D., Qiu, G., Jin, X., Hu, X. \& Chen, G. Z. Electrochemical metallization of solid terbium oxide. Angew. Chem. Int. Ed. 45, 2384-2388 (2006).

10. Yin, H. et al. Faradaically selective membrane for liquid metal displacement batteries. Nat. Energy 3, 127-131 (2018).

11. Lin, M. C. et al. An ultrafast rechargeable aluminium-ion battery. Nature $\mathbf{5 2 0}$, 325-328 (2015).

12. Wang, K. et al. Lithium-antimony-lead liquid metal battery for grid-level energy storage. Nature 514, 348-350 (2014).

13. Jiao, H., Wang, C., Tu, J., Tian, D. \& Jiao, S. A rechargeable Al-ion battery: Al/ molten $\mathrm{AlCl}_{3}$-urea/graphite. Chem. Commun. 53, 2331-2334 (2017).

14. Lang, J. et al. High-purity electrolytic lithium obtained from low-purity sources using solid electrolyte. Nat. Sustain. 3, 386-390 (2020).

15. Till, C. E. \& Chang, Y. I. Plentiful Energy: The Story of the Integral Fast Reactor (CreateSpace, 2011).

16. Gaune-Escard, M. \& Haarberg, G. M. Molten Salts Chemistry and Technology (Wiley, 2014).

17. Zhang, M. et al. New formulation for reduction potentials of $(\mathrm{Cu}, \mathrm{Ni}, \mathrm{Al}$, $\mathrm{Zn}$ )-lanthanide alloys-implications for electrolysis-based pyroprocessing of spent nuclear fuel. Electrochem. Commun. 93, 180-182 (2018).

18. Zhang, J. S. Electrochemistry of actinides and fission products in molten saltsdata review. J. Nucl. Mater. 447, 271-284 (2014).

19. Guo, S. Q., Zhang, J. S., Wu, W. \& Zhou, W. T. Corrosion in the molten fluoride and chloride salts and materials development for nuclear applications. Prog. Mater. Sci. 97, 448-487 (2018).

20. Stafford, G. R., \& Hussey, C. L. Electrodeposition of Transition Metal-Aluminum Alloys from Chloroaluminate Molten Salts Ch. 6 (Wiley-VCH, 2002).

21. Boston, C. Molten Salt Chemistry of the Haloaluminates Ch. 3 (Springer, 1971).

22. Gilbert, B., Mamantov, G. \& Fung, K. W. Electrochemistry of zirconium(IV) in chloroaluminate melts. Inorg. Chem. 14, 1802-1806 (1975).

23. D'olieslager, W., Meuris, F. \& Heerman, L. Electrochemistry of uranium in sodium chloroaluminate melts. J. Radioanal. Nucl. Chem. 143, 199-211 (1990).

24. Polovov, I. B. et al. In situ spectroscopy and spectroelectrochemistry of uranium in high-temperature alkali chloride molten salts. Inorg. Chem. 47, 7474-7482 (2008).

25. Liu, Y.-L. et al. Confirmation and elimination of cyclic electrolysis of uranium ions in molten salts. Electrochem. Commun. 103, 55-60 (2019).
26. Liu, K. et al. Electrochemical properties of uranium on the liquid Gallium electrode in LiCl-KCl eutectic. J. Electrochem. Soc. 163, D554-D561 (2016).

27. Hoover, R. O., Shaltry, M. R., Martin, S., Sridharan, K. \& Phongikaroon, S. Electrochemical studies and analysis of $1-10 \mathrm{wt} \% \mathrm{UCl}_{3}$ concentrations in molten LiCl-KCl eutectic. J. Nucl. Mater. 452, 389-396 (2014).

28. Sekimoto, H., Nose, Y., Uda, T. \& Sugimura, H. Preparation and properties of trivalent titanium compounds, $\mathrm{TiCl}_{3}$ and TiOCl. High Temp. Mater. Process. 30, 435-440 (2011).

29. Farber, M. \& Darnell, A. The disproportionation and vapor pressure of $\mathrm{TiCl}_{3}$. J. Phys. Chem. 59, 156-159 (1955)

30. Zhang, H. et al. Stable colloids in molten inorganic salts. Nature 542, 328-331 (2017).

31. Le Bideau, J., Viau, L. \& Vioux, A. Ionogels, ionic liquid based hybrid materials. Chem. Soc. Rev. 40, 907-925 (2011).

32. Wang, H., Gurau, G. \& Rogers, R. D. Ionic liquid processing of cellulose. Chem. Soc. Rev. 41, 1519-1537 (2012).

33. Boxall, L. G., Jones, H. L. \& Osteryoung, R. A. Solvent equilibria of AICl-NaCl melts. J. Electrochem. Soc. 120, 233-231 (1973).

34. Wang, L. et al. Effective removal of anionic Re(VII) by surface-modified $\mathrm{Ti}_{2} \mathrm{CTx}$ MXene nanocomposites: implications for $\mathrm{Tc}(\mathrm{VII})$ sequestration. Environ. Sci. Technol. 53, 3739-3747 (2019).

\section{Acknowledgements}

We are thankful for the support from the National Science Fund for Distinguished Young Scholars (21925603) and the Major Program of the National Natural Science Foundation of China (No.21790373). We also thank Dr. Lei Zhang from Ningbo Institute of Industrial Technology, Chinese Academy of Sciences, for her helpful discussions in manuscript preparation. The work of J.K.G. was supported by the U.S. Department of Energy, Office of Basic Energy Sciences, Heavy Element Chemistry Program at LBNL under Contract NO. DEAC02-05CH11231.

\section{Author contributions}

W.Q.S. and Z.F.C. conceived and supervised the project. W.Q.S., Y.K.Z., and Y.L.L. designed the experiments. Y.K.Z. and Y.L.L. carried out the uptake experiments wrote the paper. W.Q.S. and J.K.G. reviewed and edited the paper. L.W. performed the EXAFS and SEM-EDS analysis. K.L., L.M., J.Z.C., S.L.J., Y.C.L., and L.Y.Y. offered experimental help All authors discussed the results and commented on the manuscript.

\section{Competing interests}

The authors declare no competing interests.

\section{Additional information}

Supplementary information The online version contains supplementary material available at https://doi.org/10.1038/s41467-021-26119-9.

Correspondence and requests for materials should be addressed to Ya-Lan Liu or Wei-Qun Shi.

Peer review information Nature Communications thanks Pavel Soucek and the other anonymous, reviewer for their contribution to the peer review of this work

Reprints and permission information is available at http://www.nature.com/reprints

Publisher's note Springer Nature remains neutral with regard to jurisdictional claims in published maps and institutional affiliations.

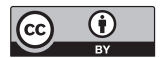

Open Access This article is licensed under a Creative Commons Attribution 4.0 International License, which permits use, sharing, adaptation, distribution and reproduction in any medium or format, as long as you give appropriate credit to the original author(s) and the source, provide a link to the Creative Commons license, and indicate if changes were made. The images or other third party material in this article are included in the article's Creative Commons license, unless indicated otherwise in a credit line to the material. If material is not included in the article's Creative Commons license and your intended use is not permitted by statutory regulation or exceeds the permitted use, you will need to obtain permission directly from the copyright holder. To view a copy of this license, visit http://creativecommons.org/ licenses/by/4.0/.

(C) The Author(s) 2021 